ARTICLE

\title{
A high-throughput neutralizing antibody assay for COVID-19 diagnosis and vaccine evaluation
}

\author{
Antonio E. Muruato $1,2,10$, Camila R. Fontes-Garfias ${ }^{1,10}$, Ping Ren ${ }^{3,10}$, Mariano A. Garcia-Blanco (1) 1,4,5, \\ Vineet D. Menachery $2,3,6$, Xuping Xie (1) ${ }^{1 凶} \&$ Pei-Yong Shi (1) $1,6,7,8,9 凶$
}

Virus neutralization remains the gold standard for determining antibody efficacy. Therefore, a high-throughput assay to measure SARS-CoV-2 neutralizing antibodies is urgently needed for COVID-19 serodiagnosis, convalescent plasma therapy, and vaccine development. Here, we report on a fluorescence-based SARS-CoV-2 neutralization assay that detects SARS-CoV-2 neutralizing antibodies in COVID-19 patient specimens and yields comparable results to plaque reduction neutralizing assay, the gold standard of serological testing. The fluorescence-based neutralization assay is specific to measure COVID-19 neutralizing antibodies without cross reacting with patient specimens with other viral, bacterial, or parasitic infections. Collectively, our approach offers a rapid platform that can be scaled to screen people for antibody protection from COVID-19, a key parameter necessary to safely reopen local communities.

\footnotetext{
${ }^{1}$ Department of Biochemistry and Molecular Biology, University of Texas Medical Branch, Galveston, TX, USA. ${ }^{2}$ Department of Microbiology and Immunology, University of Texas Medical Branch, Galveston, TX, USA. ${ }^{3}$ Department of Pathology, University of Texas Medical Branch, Galveston, TX, USA

${ }^{4}$ Programme in Emerging Infectious Diseases, Duke-NUS Medical School, Singapore, Singapore. ${ }^{5}$ Department of Internal Medicine, University of Texas Medical Branch, Galveston, TX, USA. ${ }^{6}$ Institute for Human Infections and Immunity, University of Texas Medical Branch, Galveston, TX, USA. ${ }^{7}$ Sealy Institute for Vaccine Sciences, University of Texas Medical Branch, Galveston, TX, USA. ${ }^{8}$ Sealy Center for Structural Biology \& Molecular Biophysics, University of Texas Medical Branch, Galveston, TX, USA. ${ }^{9}$ Institute for Translational Science, University of Texas Medical Branch, Galveston, TX, USA.

${ }^{10}$ These authors contributed equally: Antonio E. Muruato, Camila R. Fontes-Garfias, Ping Ren. ${ }^{凶}$ email: xuxie@UTMB.edu; peshi@UTMB.edu
} 
$\mathrm{T}$ he ongoing coronavirus disease 2019 (COVID-19) pandemic is caused by severe acute respiratory syndrome coronavirus 2 (SARS-CoV-2), first reported in Wuhan, China in late $2019^{1,2}$. As of June 28, 2020, COVID-19 has caused 10.3 million confirmed infections and over 505,741 deaths worldwide (https://www.worldometers.info/coronavirus/). Many areas of the world have been in lockdown mode to curb the viral transmission, but the reality is that COVID-19 is here to stay until a safe and efficacious vaccine becomes available. The pandemic's catastrophic economic impact is pushing governments to reopen their economies, and this creates a public health quandary. At this time, our only option is to minimize viral transmission through social distancing and contact tracing, which relies on the diagnosis of viral RNA through reverse transcription polymerase chain reaction (RT-PCR) (https://www.fda.gov/media/134922/ download). Proper public health policy would be greatly enhanced if we had a reliable and facile assay to measure the immune protection among COVID-19 recovered patients.

Coronavirus infections typically induce neutralizing antibody responses ${ }^{3}$. The seroconversion rates in COVID-19 patients are $50 \%$ and $100 \%$ on day 7 and 14 post symptom onset, respectively ${ }^{4}$. Given the unknown scale of asymptomatic infections, there is a pressing need for serological diagnosis to determine the real number of infections. Such information is essential for defining the case-fatality rate and for making the policy on the scale and duration of social lockdowns. The serological assays are also required to identify donors with high-neutralizing titers for convalescent plasma for therapy, and to define correlates of protection from SARS-CoV-2. While viral RNA-based testing for acute infection is the current standard, surveying antibody protection is a necessary part of any return to social normality.

For serodiagnosis, several COVID-19 assay platforms have achieved FDA emergency use authorizations (EUA), including ELISA $^{5}$ (https://www.fda.gov/media/137029/download), lateral flow immunoassay (https://www.fda.gov/media/136625/download), and Microsphere Immunoassay (https://www.fda.gov/media/137541/ download). These assays measure antibody binding to SARSCoV-2 spike protein. Since not all spike-binding antibodies can block viral infection, these platforms do not functionally measure antibody inhibition of SARS-CoV-2 infection. An ideal serological assay should measure neutralizing antibody levels, which should predict protection from reinfection. Conventionally, neutralizing antibodies are measured by plaque reduction neutralization test (PRNT). Although PRNT and ELISA results generally corelate with each other, particularly when the receptor-binding domain of SARS-CoV-2 spike protein is used as an ELISA antigen (https:// www.genscript.com/cpass-sars-cov-2-neutralization-antibody-

detection-Kit.html) ${ }^{6,7}$, PRNT remains the gold standard for serological testing and determining immune protection ${ }^{8,9}$. However, due to its low throughput, PRNT is not practical for large scale serodiagnosis and vaccine evaluation. This is a major gap for COVID-19 surveillance and vaccine development.

Here, we report a fluorescence-based high-throughput neutralization assay that detects SARS-CoV-2 neutralizing antibodies in patient specimens and yields equivalent results to the gold standard plaque reduction neutralizing assay.

\section{Results}

A high-throughput fluorescence-based neutralization assay. To fill in the gap for COVID-19 serodiagnosis and vaccine evaluation, we developed a fluorescence-based assay that rapidly and reliably measures neutralization of a reporter SARS-CoV-2 by antibodies from patient specimens. The assay was built on a stable mNeonGreen (mNG) SARS-CoV-2 where the $\mathrm{mNG}$ gene was engineered at the ORF7 of the viral genome (Fig. 1a) ${ }^{10}$. The complete sequence of mNG SARS-CoV-2 is described in Supplementary Fig. 1. Figure $1 \mathrm{~b}$ depicts the flowchart of the reporter neutralization assay in a 96-well format. The assay protocol is detailed in Supplementary Methods. Briefly, patient sera were serially diluted and incubated with the reporter virus. After incubation at $37^{\circ} \mathrm{C}$ for $1 \mathrm{~h}$, Vero CC-81 cells (pre-seeded in a 96well plate) were infected with the virus/serum mixtures at a multiplicity of infection (MOI) of 0.5 . At $16 \mathrm{~h}$ post-infection, the mNG-positive cells were quantitated using a high-content imaging reader (Fig. 1b). It should be noted that Vero CC-81 cells, not Vero E6 cells, were chosen for the mNG assay to enable accurate quantification of fluorescent cells. Sixty COVID-19 serum specimens from RT-PCR-confirmed patients and 60 nonCOVID-19 serum samples (archived before COVID-19 emergence) were analyzed using the reporter virus. For some COVID19-positive specimens, the sample collection days post viral RTPCR positive were available and are indicated in Table 1. After reporter viral infection, the cells turned green in the absence of serum (Fig. 1c, bottom panel); in contrast, incubation of the reporter virus with COVID-19 patient serum decreased the number of fluorescent cells (top panel). A dose-response curve was obtained between the number of fluorescent cells and the fold of serum dilution (Fig. 1d and Supplementary Fig. 2), which allowed for determination of the dilution fold that neutralized $50 \%$ of fluorescent cells $\left(\mathrm{NT}_{50}\right)$. The reporter assay rapidly diagnosed 120 specimens within $24 \mathrm{~h}$ : all 60 COVID-19 sera (specimens 1-60) showed positive $\mathrm{NT}_{50}$ of 35 to 5711 , and all 60 non-COVID-19 sera (specimens 61-120) showed negative $\mathrm{NT}_{50}$ of $<20$ (Table 1 ).

Assay validation by plaque reduction test. To validate the reporter virus neutralization results, we performed the conventional PRNT on the same set of patient specimens. All 60 negative sera (specimens 61-120) exhibited $\mathrm{PRNT}_{50}$ of $<20$ (Table 1). Among the 60 positive specimens, 57 sera (specimens 4-60) showed $\mathrm{PRNT}_{50}$ of 40 to 3200 , whereas 3 sera (specimens 1-3) exhibited $\mathrm{PRNT}_{50}$ of $<20$ (Table 1). The discrepancy between the $\mathrm{PRNT}_{50}$ and $\mathrm{NT}_{50}$ values for specimens 1-3 is likely due to the early infection time (within 5 days post RT-PCR positive) when neutralizing antibodies just began to develop; this discrepancy suggests that the mNG SARS-CoV-2 assay has a higher sensitivity than the conventional PRNT assay. Nevertheless, a strong correlation was observed between the reporter virus and PRNT results, with a correlation efficiency $R^{2}$ of 0.85 (Fig. 1e). The results demonstrate that when diagnosing patient specimens, the reporter virus assay delivers neutralization results comparable to the PRNT assay, the gold standard of serological testing.

Assay specificity. We evaluated the specificity of reporter neutralization assay using potentially cross-reactive sera and interfering substances (Table 2). Two groups of specimens were tested for cross reactivity. Group I included 150 clinical sera from patients with antigens or antibodies against different viruses, bacteria, and parasites. These human specimens were obtained according to two types of diagnostic results: some samples were tested positive for antibodies against specific pathogens (e.g., antiChikungunya virus; this group of samples are indicated by prefix "anti" in Table 2); other specimens were collected within 1 to 6 months after the patients were tested positive on pathogen antigens or nucleic acids (e.g., adenovirus antigen; this group of samples are not indicated by prefix in Table 2). Group II consisted of 19 samples with albumin, elevated bilirubin, cholesterol, rheumatoid factor, and autoimmune nuclear antibodies. None of these specimens cross-neutralized mNG SARS-CoV-2 (Table 2), including the four common cold coronaviruses (NL63, 229E, 
a

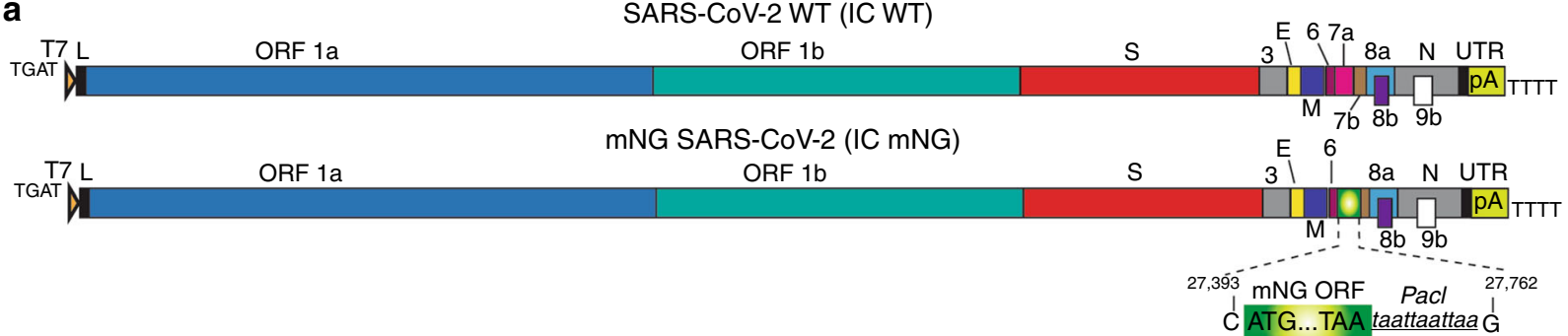

b

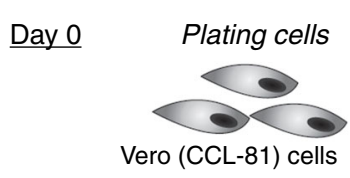

Day 1 Infection

Mixing serum\& reporter viruses

IC mNG (MOI 0.5)

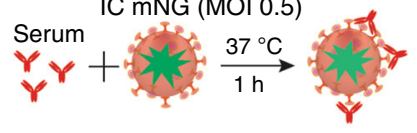

Day 2 Data acquistion \& analysis

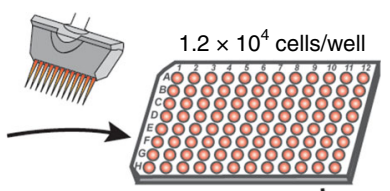

Overnight

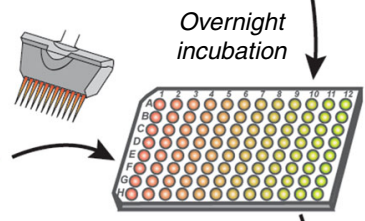

$16 \mathrm{~h}$

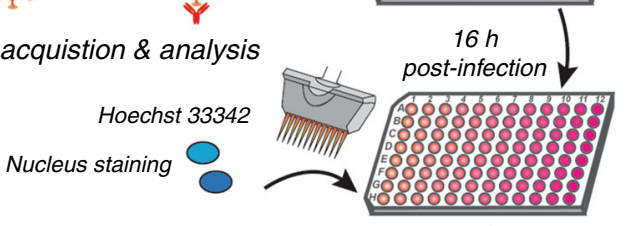

1) Counting the $\mathrm{mNG}^{+}$cells;

2) Calculate infection rate $\& N T_{50} s$

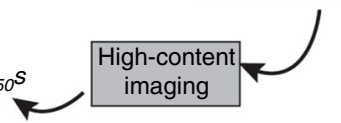

C Positive serum (neutralized)

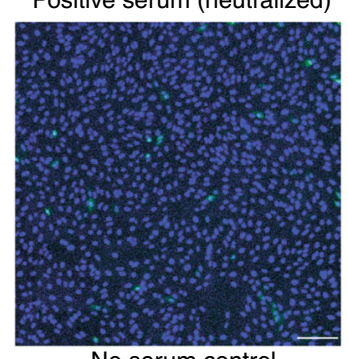

No serum control

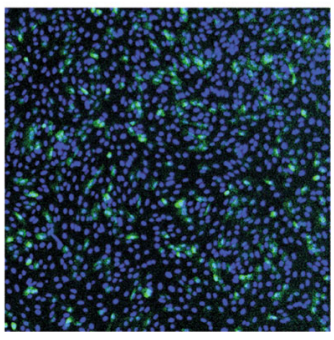

d
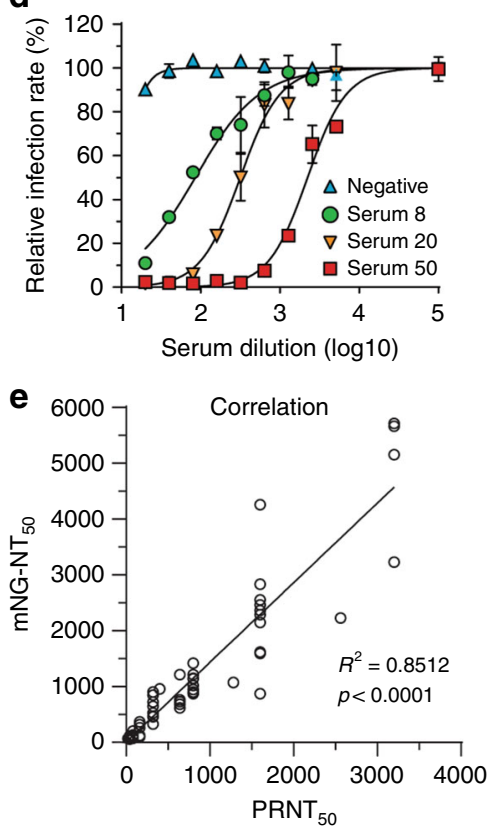

Fig. 1 A high-throughput neutralizing antibody assay for COVID-19 diagnosis. a Diagram of the cDNA constructs of wild-type (WT) SARS-CoV-2 (top panel) and $\mathrm{mNG}$ SARS-CoV-2 (bottom panel). The nucleotide positions of viral genome where $\mathrm{mNG}$ is engineered are indicated. $\mathbf{b}$ Assay flowchart. mNG SARS-CoV-2 was neutralized with COVID-19 patient sera. Vero CCL-81 cells were infected with the reporter virus/serum mixture with an MOI of 0.5. The fluorescence of infected cells was quantified to estimate the $\mathrm{NT}_{50}$ value for each serum. c Representative images of reporter virus-infected Vero CCL-81 cells. Images for a positive neutralizing serum (top panel) and no serum control (bottom panel) are presented. Scale bar, $100 \mu \mathrm{m}$. $\mathbf{d}$ Neutralization curves. Representative neutralization curves are presented for three positive sera and one negative sera. The means and standard deviations from two independent experiments are presented. e Correlation analysis of $\mathrm{NT}_{50}$ values between the reporter virus and PRNT assays. The Pearson correlation efficiency $R^{2}$ and $p$ value (two-tailed) are indicated.

OC43, and HUK1). Despite the low number of common cold coronavirus serum specimens, our result is consistent with the recent reports that sera from common cold coronavirus patients did not cross react with SARS-CoV-2 5,11 . More specimens are required to further validate the cross reactivity, particularly between SARS-CoV-2 and other human coronaviruses, including SARS-CoV-1 and MERS-CoV.

\section{Discussion}

In this study, we developed a rapid fluorescence-based highthroughput assay for COVID-19 serodiagnosis. The reporter virus assay is superior to many antigen/antibody binding assays because it measures functional SARS-CoV-2 neutralizing activity in the specimens. When diagnosing patient sera, the reporter virus assay generated $\mathrm{NT}_{50}$ values comparable to the conventional PRNT assay. Compared with the PRNT assay, our reporter neutralization test has shortened the assay turnaround time by several days and increased the testing capacity to high throughput. Toward the same direction, VSV and lentivirus pseudotyped with SARS-CoV-2 spike protein have been reported for COVID19 neutralization assays at biosafety level 2 (BSL-2) lab ${ }^{12}$.
Since mNG SARS-CoV-2 is stable and replicates like wild-type virus, our reporter neutralization assay provides an ideal model for high-throughput serological testing. As the mNG SARS-CoV2 grows to $>10^{7} \mathrm{PFU} / \mathrm{ml}$ in cell culture ${ }^{10}$, the reporter virus can be easily scaled up for testing large sample volumes. Besides $\mathrm{mNG}$, we have begun to develop other reporter SARS-CoV-2 (e.g., luciferase or mCherry) that can also be used for such serological testing ${ }^{13}$. Although the current study performed the assay in a 96-well format, the assay can be readily adapted to 384- and 1536-well formats. Despite the strengths of high throughput and reliability, the current reporter neutralization assay must be performed in BSL-3 containment. Efforts are ongoing to engineer an attenuated version of SARS-CoV-2 so that the assay could be performed at a BSL-2 facility. Despite the BSL-3 limitation, the $\mathrm{mNG}$ reporter assay offers a rapid, high-throughput platform to test COVID-19 patient sera not previously available. Indeed, the mNG SARS-CoV-2 assay is currently being used to support clinical trials for COVID-19 vaccine candidates ${ }^{14}$.

As neutralizing titer is a key parameter to predict immunity, the reporter neutralization assay should be useful for highthroughput evaluation of COVID-19 vaccines and for 

Table 1 Comparison of neutralization titers of patient sera
analyzed by reporter assay and plaque reduction assay.

\begin{tabular}{|c|c|c|c|c|c|}
\hline $\begin{array}{l}\text { aSerum } \\
\text { ID }\end{array}$ & CPRNT $_{50}$ & $\begin{array}{l}\text { cmNG- } \\
\text { NT }_{50}\end{array}$ & $\begin{array}{l}\text { aSerum } \\
\text { IDb }\end{array}$ & ${ }^{{ }^{C} P R N T_{50}}$ & $\begin{array}{l}\text { cmNG- } \\
\text { NT }_{50}\end{array}$ \\
\hline 1 (d1) & $<20$ & 35 & 32 (d9) & 640 & 762 \\
\hline $2(d 5)$ & $<20$ & 38 & $33(d 8)$ & 320 & 846 \\
\hline $3(d 4)$ & $<20$ & 50 & 34 (d14) & 800 & 873 \\
\hline $4(d 5)$ & 40 & 58 & 35 (d16) & 1600 & 874 \\
\hline $5(d 5)$ & 20 & 66 & 36 (d17) & 320 & 900 \\
\hline $6(d 6)$ & 80 & 74 & $37(d 9)$ & 800 & 902 \\
\hline $7(\mathrm{~d} 8)$ & 80 & 77 & 38 (d15) & 800 & 949 \\
\hline $8(d 4)$ & 80 & 85 & 39 (d15) & 400 & 958 \\
\hline $9(\mathrm{~d} 5)$ & 80 & 85 & $40(\mathrm{~d} 18)$ & 800 & 1016 \\
\hline 10 (d1) & 80 & 95 & $41(d 28)$ & 1280 & 1072 \\
\hline $11(d 6)$ & 80 & 96 & 42 (d12) & 800 & 1139 \\
\hline 12 (NA) & 160 & 96 & 43 (d13) & 800 & 1145 \\
\hline $13(\mathrm{~d} 6)$ & 40 & 111 & 44 (d14) & 800 & 1210 \\
\hline $14(d 6)$ & 40 & 114 & $45(d 31)$ & 640 & 1213 \\
\hline 15 (d1) & 80 & 115 & $46(d 8)$ & 800 & 1419 \\
\hline 16 (d9) & 160 & 120 & 47 (d14) & 1600 & 1590 \\
\hline 17 (d11) & 80 & 132 & $48(d 21)$ & 1600 & 1617 \\
\hline $18(\mathrm{~d} 8)$ & 80 & 200 & 49 (d12) & 1600 & 2148 \\
\hline 19 (NA) & 160 & 261 & 50 (NA) & 2560 & 2225 \\
\hline $20(d 5)$ & 160 & 318 & $51(d 20)$ & 1600 & 2287 \\
\hline $21(\mathrm{~d} 32)$ & 320 & 329 & $52(d 8)$ & 1600 & 2362 \\
\hline $22(\mathrm{~d} 14)$ & 160 & 365 & $53(\mathrm{~d} 12)$ & 1600 & 2463 \\
\hline $23(\mathrm{~d} 12)$ & 160 & 366 & $54(\mathrm{~d} 18)$ & 1600 & 2554 \\
\hline $24(\mathrm{~d} 37)$ & 320 & 456 & 55 (d16) & 1600 & 2832 \\
\hline 25 (NA) & 320 & 474 & $56(d 15)$ & 3200 & 3228 \\
\hline $26(d 47)$ & 320 & 525 & $57(d 31)$ & 3200 & 4257 \\
\hline $27(\mathrm{~d} 12)$ & 640 & 617 & 58 (NA) & 3200 & 5152 \\
\hline 28 (d9) & 320 & 649 & $59(d 8)$ & 3200 & 5662 \\
\hline $29(\mathrm{~d} 10)$ & 640 & 681 & 60 (NA) & 3200 & 5711 \\
\hline $30(d 27)$ & 320 & 721 & $61-120$ & $<20$ & $<20$ \\
\hline 31 (d9) & 640 & 727 & & & \\
\hline
\end{tabular}

a total of 120 patient sera were analyzed, including 60 specimens from RT-PCR-confirmed patients (specimens 1-60) and 60 negative specimens (specimens 61-120) that were collected before COVID-19 pandemic (prepandemic).

bSample collection days post after RT-PCR positive test are indicated in parentheses. For some COVID-19-positive specimens, the sample collection days post after RT-PCR positive test are not available (NA).

${ }^{\text {cThe }} \mathrm{NT}_{50}$ and PRNT ${ }_{50}$ values were derived from the reporter virus assay and conventional PRNT assay, respectively.

identification of high-neutralizing convalescent plasma for therapy. Treatment of severe COVID-19 patients with convalescent plasma shows clinical benefits ${ }^{15}$. For vaccine development, a standardized neutralizing assay will facilitate down selection of various candidates for clinical development. Furthermore, the reporter assay could be used over time to monitor the waning of protective neutralizing titers in COVID-19 patients and vaccinated individuals, to study the correlates of protection from SARS-CoV-2, and to monitor high-risk populations (such as healthcare workers) for infection prevention. Thus, the ability to rapidly measure neutralizing antibody levels in populations is essential for guiding policymakers to reopen the economy and society, deploy healthcare workers, and prepare for SARS-CoV-2 reemergence.

\section{Methods}

Cells. Vero (ATCC ${ }^{\oplus}$ CCL-81) and Vero E6 (ATCC ${ }^{\circledR}$ CRL-1586) were purchased from the American Type Culture Collection (ATCC, Bethesda, MD), and maintained in a high-glucose Dulbecco's modified Eagle's medium (DMEM) supplemented with $10 \%$ fetal bovine serum (FBS; HyClone Laboratories, South Logan, UT) and $1 \%$ penicillin/streptomycin at $37^{\circ} \mathrm{C}$ with $5 \% \mathrm{CO}_{2}$. All culture medium and antibiotics were purchased from ThermoFisher Scientific (Waltham, MA). All cell lines were tested negative for mycoplasma.
Table 2 Cross reactivity of $\mathbf{m N G}$ SARS-CoV-2 neutralization assay.

\begin{tabular}{|c|c|c|}
\hline $\begin{array}{l}\text { almmune sera and } \\
\text { binterfering substances }\end{array}$ & Sample number & $\begin{array}{l}\text { Number of } \mathbf{m N G} \\
\text { tested positive }\end{array}$ \\
\hline Adenovirus & 1 & 0 \\
\hline Anti-Chikungunya virus & 4 & 0 \\
\hline $\begin{array}{l}\text { Cryptococcus neoformans } \\
\text { antigen }\end{array}$ & 2 & 0 \\
\hline Anti-Cytomegalovirus & 8 & 0 \\
\hline Anti-Dengue virus & 5 & 0 \\
\hline $\begin{array}{l}\text { Anti-Epstein Barr Virus: } \\
\text { capsid or nuclear antigen }\end{array}$ & 8 & 0 \\
\hline Anti-Hepatitis A virus & 5 & 0 \\
\hline $\begin{array}{l}\text { Anti-Hepatitis B virus: } \\
\text { surface antigen }\end{array}$ & 15 & 0 \\
\hline Anti-Hepatitis C virus & 3 & 0 \\
\hline Anti-Herpes simplex virus 1 & 7 & 0 \\
\hline Anti-Herpes simplex virus 2 & 5 & 0 \\
\hline Human coronavirus 229E & 1 & 0 \\
\hline Human coronavirus HKU1 & 5 & 0 \\
\hline Human coronavirus NL63 & 1 & 0 \\
\hline Human coronavirus OC43 & 4 & 0 \\
\hline $\begin{array}{l}\text { Anti-Human } \\
\text { immunodeficiency virus } 1\end{array}$ & 10 & 0 \\
\hline Human rhinovirus & 3 & 0 \\
\hline Influenza B virus & 2 & 0 \\
\hline Anti-Measles virus & 7 & 0 \\
\hline Anti-Mumps virus & 5 & 0 \\
\hline Parainfluenza virus 2 & 1 & 0 \\
\hline Parainfluenza virus 4 & 1 & 0 \\
\hline Anti-Parvovirus B19 & 4 & 0 \\
\hline Respiratory syncitial virus & 1 & 0 \\
\hline Anti-Rubella virus & 12 & 0 \\
\hline Anti-Syphilis & 5 & 0 \\
\hline Anti-Toxoplasma & 2 & 0 \\
\hline Anti-Typhus Fever & 1 & 0 \\
\hline Anti-Varicella zoster virus & 13 & 0 \\
\hline Anti-West Nile Virus & 3 & 0 \\
\hline Anti-Yellow fever virus: & 2 & 0 \\
\hline
\end{tabular}

vaccination

Anti-Zika virus

bAlbumin $(4.5 \mathrm{~g} / \mathrm{dl})$

bElevated bilirubin

conjugated (>0.4 mg/dl)

bElevated bilirubin

unconjugated $(>0.8 \mathrm{mg} / \mathrm{dl}$ )

bElevated cholesterol ( $>200$ $\mathrm{mg} / \mathrm{dl}$ )

bElevated rheumatoid factor (>100 IU/ml)

${ }^{b}$ Anti-nuclear antibodies

$\begin{array}{ll}4 & 0 \\ 3 & 0 \\ 3 & 0\end{array}$

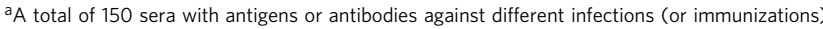
were tested against $\mathrm{mNG}$ SARS-CoV-2 neutralization assay. The immune sera are listed in alphabetical order. Samples tested positive for antibodies against specific pathogens are indicated with prefix "anti", whereas samples tested positive on antigens or pathogen nucleic acids are not indicated with prefix. For the latter group, the specimens were collected within 1 to 6 months after the antigen or PCR tested positive.

6 months after the antigen or PCR tested positive.
${ }^{b}$ A total of 19 samples tested for interfering substances and autoimmune disease nuclear bA total of 1958 antibodies.
a

mNG SARS-CoV-2. The virus stock of mNG SARS-CoV-2 was produced using an infectious complementary DNA (cDNA) clone of SARS-CoV-2 in which the ORF7 of the viral genome was replaced with reporter $\mathrm{mNG}$ gene ${ }^{10}$. After rescued from the genome-length viral RNA-electroporated cells, the viral stock was prepared by amplifying the mNG SARS-CoV-2 on Vero E6 cells for one or two rounds. The titer of the virus stock was determined by a standard plaque assay.

Human sera and interfering substances. The research protocol regarding the use of human serum specimens was reviewed and approved by the University of Texas Medical Branch (UTMB) Institutional Review Board. The approved IRB protocol 
number is 20-0070. All human serum specimens were obtained at the UTMB. All specimens were de-identified from patient information. A total of 60 de-identified convalescent sera from COVID-19 patients (confirmed with viral RT-PCR positive) were tested in this study. Sixty non-COVID-19 sera, collected before COVID-19 emergence $\mathrm{e}^{16,17}$, were also tested in the reporter virus and PRNT assays. For testing cross reactivity, a total of 150 de-identified specimens from patients with antigens or antibodies against different viruses, bacteria, and parasites were tested in the $\mathrm{mNG}$ SARS-COV-2 neutralization assay (Table 2). For testing interfering substances, 19 deidentified serum specimens with albumin, elevated bilirubin, cholesterol, rheumatoid factor, and autoimmune nuclear antibodies were tested in the reporter neutralization assay. All human sera were heat-inactivated at $56^{\circ} \mathrm{C}$ for $30 \mathrm{~min}$ before testing.

mNG SARS-CoV-2 reporter neutralization assay. Vero CCL-81 cells $\left(1.2 \times 10^{4}\right)$ in $50 \mu \mathrm{l}$ of DMEM (Gibco) containing 2\% FBS (Hyclone) and $100 \mathrm{U} / \mathrm{ml}$ Penicillium-Streptomycin (P/S; Gibco) were seeded in each well of black $\mu$ CLEAR flat-bottom 96-well plate (Greiner Bio-one ${ }^{\mathrm{mm}}$ ). Vero CCL-81 cells, not Vero E6 cells, were selected for the mNG SARS-COV-2 assay to facilitate accurate quantification of fluorescent cells by high-content imaging. The cells were incubated overnight at $37^{\circ} \mathrm{C}$ with $5 \% \mathrm{CO}_{2}$. On the following day, each serum was twofold serially diluted in $2 \% \mathrm{FBS}$ and $100 \mathrm{U} / \mathrm{ml} \mathrm{P/S} \mathrm{DMEM}$, and incubated with mNG SARS-CoV-2 at $37^{\circ} \mathrm{C}$ for $1 \mathrm{~h}$. The virus-serum mixture was transferred to the Vero CCL-81 cell plate with the final multiplicity of infection (MOI) of 0.5 . For each serum, the starting dilution was $1 / 20$ with nine two-fold dilutions to the final dilution of $1 /$ 5120. After incubating the infected cells at $37^{\circ} \mathrm{C}$ for $16 \mathrm{~h}, 25 \mu \mathrm{l}$ of Hoechst 33342 Solution (400-fold diluted in Hank's Balanced Salt Solution; Gibco) were added to each well to stain cell nucleus. The plate was sealed with Breath-Easy sealing membrane (Diversified Biotech), incubated at $37^{\circ} \mathrm{C}$ for $20 \mathrm{~min}$, and quantified for mNG fluorescence on Cytation ${ }^{\mathrm{TM}} 7$ (BioTek). The raw images $(2 \times 2$ montage) were acquired using $4 \times$ objective, processed, and stitched using the default setting. The total cells (indicated by nucleus staining) and $\mathrm{mNG}$-positive cells were quantified for each well. Infection rates were determined by dividing the mNGpositive cell number to total cell number. Relative infection rates were obtained by normalizing the infection rates of serum-treated groups to those of non-serumtreated controls. The curves of the relative infection rates versus the serum dilutions ( $\log 10$ values) were plotted using Prism 8 (GraphPad). A nonlinear regression method was used to determine the dilution fold that neutralized $50 \%$ of $\mathrm{mNG}$ fluorescence $\left(\mathrm{NT}_{50}\right)$. Each serum was tested in duplicates. All mNG SARS-CoV-2 reporter neutralization assay was performed at the BSL-3 facility at UTMB.

Plaque reduction neutralization test (PRNT). Vero E6 cells $\left(1.2 \times 10^{6}\right.$ per well) were seeded to six-well plates. On the following day, $100 \mathrm{PFU}$ of infectious clonederived wild-type SARS-CoV-2 was incubated with serially diluted serum (total volume of $200 \mu \mathrm{l}$ ) at $37^{\circ} \mathrm{C}$ for $1 \mathrm{~h}$. The virus-serum mixture was added to the preseeded Vero E6 cells. After $1 \mathrm{~h} 37^{\circ} \mathrm{C}$ incubation, $2 \mathrm{ml}$ of $2 \%$ high gel temperature agar (SeaKem) in DMEM containing 5\% FBS and $1 \% \mathrm{P} / \mathrm{S}$ was added to the infected cells. After 2 days of incubation, $2 \mathrm{ml}$ neutral red ( $1 \mathrm{~g} / \mathrm{l}$ in PBS; Sigma) was added to the agar-covered cells. After another 5-h incubation, neutral red was removed. Plaques were counted for $\mathrm{NT}_{50}$ calculation. Each serum was tested in duplicates. The PRNT assay was performed at the BSL-3 facility at UTMB.

Statistical analysis. The correlation of the $\mathrm{NT}_{50}$ values from $\mathrm{mNG}$ reporter SARS$\mathrm{CoV}-2$ assay and the $\mathrm{PRNT}_{50}$ values from plaque neutralization assay was analyzed using a linear regression model in the software Prism 8 (GraphPad). Pearson correlation coefficient and two-tailed $p$-value are calculated using the default settings in the software Prism 8 .

Reporting summary. Further information on research design is available in the Nature Research Reporting Summary linked to this article.

\section{Data availability}

Source data are provided with this paper. The assay protocol and sequence of $\mathrm{mNG}$ reporter SARS-CoV-2 are provided in the Supplementary Information. The mNG reporter SARS-CoV-2 has been deposited to the World Reference Center for Emerging Viruses and Arboviruses (https://www.utmb.edu/wrceva) at UTMB for distribution.

Received: 20 May 2020; Accepted: 19 July 2020;

Published online: 13 August 2020

\section{References}

1. Zhou, P. et al. A pneumonia outbreak associated with a new coronavirus of probable bat origin. Nature 579, 270-273 (2020)

2. Zhu, N. et al. A novel coronavirus from patients with pneumonia in China, 2019. N. Engl. J. Med. 382, 727-733 (2020)
3. Huang, A. T. et al. A systematic review of antibody mediated immunity to coronaviruses: antibody kinetics, correlates of protection, and association of antibody responses with severity of disease. medRxiv https://doi.org/10.1101/ 2020.04.14.20065771 (2020).

4. Wolfel, R. et al. Virological assessment of hospitalized patients with COVID2019. Nature https://doi.org/10.1038/s41586-020-2196-x (2020).

5. Amanat, F. et al. A serological assay to detect SARS-CoV-2 seroconversion in humans. Nat. Med. https://doi.org/10.1038/s41591-020-0913-5 (2020).

6. GeurtsvanKessel, C. H. et al. Towards the next phase: evaluation of serological assays for diagnostics and exposure assessment. medRxiv https://doi.org/ 10.1101/2020.04.23.20077156 (2020).

7. Harvala, H. et al. Convalescent plasma therapy for the treatment of patients with COVID-19: Assessment of methods available for antibody detection and their correlation with neutralising antibody levels. medRxiv https://doi.org/ 10.1101/2020.05.20.20091694 (2020).

8. Perera, R. A. et al. Serological assays for severe acute respiratory syndrome coronavirus 2 (SARS-CoV-2), March 2020. Euro Surveill. 25, https://doi.org/ 10.2807/1560-7917.ES.2020.25.16.2000421 (2020).

9. Okba, N. M. A. et al. Severe acute respiratory syndrome coronavirus 2-specific antibody responses in coronavirus disease 2019 patients. Emerg. Infect. Dis. 26 https://doi.org/10.3201/eid2607.200841 (2020).

10. Xie, X. et al. An infectious cDNA clone of SARS-CoV-2. Cell Host Microbe https://doi.org/10.1016/j.chom.2020.04.004 (2020)

11. Khan, S. et al. Analysis of serologic cross-reactivity between common human coronaviruses and SARS-CoV-2 using coronavirus antigen microarray. bioRxiv https://doi.org/10.1101/2020.03.24.006544 (2020).

12. Nie, J. et al. Establishment and validation of a pseudovirus neutralization assay for SARS-CoV-2. Emerg. Microbes Infect. 9, 680-686 (2020).

13. Xie, X. et al. A nanoluciferase SARS-CoV-2 for rapid neutralization testing and screening of anti-infective drugs for COVID-19. bioRxiv https://doi.org/ 10.1101/2020.06.22.165712 (2020).

14. Mulligan, M. J. et al. Phase $1 / 2$ study of a COVID-19 RNA vaccine candidate (BNT162b1) in adults. Nature (2020). In press.

15. Shen, C. et al. Treatment of 5 critically ill patients with COVID-19 with convalescent plasma. JAMA https://doi.org/10.1001/jama.2020.4783 (2020)

16. Shan, C. et al. Evaluation of a novel reporter virus neutralization test for serological diagnosis of Zika and Dengue virus infection. J. Clin. Microbiol. 55, 3028-3036 (2017)

17. Shan, C. et al. A rapid Zika diagnostic assay to measure neutralizing antibodies in patients. EBioMedicine 17, 157-162 (2017).

\section{Acknowledgements}

We thank colleagues at UTMB for helpful discussion during the course of this project. P.-Y.S. was supported by NIH grants AI134907, AI145617, and UL1TR001439, and awards from the Sealy \& Smith Foundation, Kleberg Foundation, John S. Dunn Foundation, Amon G. Carter Foundation, Gilson Longenbaugh Foundation, and Summerfield Robert Foundation. M.A.G.-B. was supported by NIH grant CA204806 and the Vacek Distinguished Chair. V.D.M. was supported by NIH grants U19AI100625, R00AG049092, R24AI120942, and STARs Award from the University of Texas System. A.E.M. is supported by a Clinical and Translational Science Award NRSA (TL1) Training Core (TL1TR001440) from NIH. C. R.F.-G. is supported by the predoctoral fellowship from the McLaughlin Fellowship Endowment at UTMB.

\section{Author contributions}

P.R., M.A.G.-B., V.D.M., X.X., and P.-Y.S. conceived the study. A.E.M. and C.R.F.-G. performed the experiments and analyzed the results. P.R. prepared the serum specimens. M.A.G.-B., V.D.M., X.X., and P.-Y.S. wrote the manuscript.

\section{Competing interests}

X.X., V.D.M., and P.-Y.S. have filed a patent on the reverse genetic system and reporter SARS-CoV-2. Other authors declare no competing interests.

\section{Additional information}

Supplementary information is available for this paper at https://doi.org/10.1038/s41467 020-17892-0.

Correspondence and requests for materials should be addressed to X.X. or P.-Y.S.

Peer review information Nature Communications thanks the anonymous reviewers for their contribution to the peer review of this work. Peer reviewer reports are available.

Reprints and permission information is available at http://www.nature.com/reprints

Publisher's note Springer Nature remains neutral with regard to jurisdictional claims in published maps and institutional affiliations. 
(c) (i) Open Access This article is licensed under a Creative Commons Attribution 4.0 International License, which permits use, sharing, adaptation, distribution and reproduction in any medium or format, as long as you give appropriate credit to the original author(s) and the source, provide a link to the Creative Commons license, and indicate if changes were made. The images or other third party material in this article are included in the article's Creative Commons license, unless indicated otherwise in a credit line to the material. If material is not included in the article's Creative Commons license and your intended use is not permitted by statutory regulation or exceeds the permitted use, you will need to obtain permission directly from the copyright holder. To view a copy of this license, visit http://creativecommons.org/ licenses/by/4.0/.

(C) The Author(s) 2020, corrected publication 2021 